MATEC Web of Conferences 13, 04014 (2014)

DOI: $10.1051 /$ matecconf/ 20141304014

(C) Owned by the authors, published by EDP Sciences, 2014

\title{
Chemical Characterization of Stabilized and Carbonized Polyacrylonitrile (PAN) Fibers Treated with Oleic Acid.
}

\author{
Shahrul Nizam Md Salleh ${ }^{1, \mathrm{a}}$, Mohamad Zaki Abdullah", ${ }^{2,}$ Azmi Abdul Wahab ${ }^{3}$, \\ 1,2,3 Mechanical Engineering Department,Universiti Teknologi PETRONAS \\ Bandar Seri Iskandar, 31750 Tronoh, Perak,Malaysia
}

\begin{abstract}
Polyacrylonitrile (PAN) fiber is the best precursor for carbon fibers due to high carbon content after heat treatment. After the polymer was spun into fibers, the fibers will undergo pretreatment process with chemical solution known as post spinning treatment. Post spinning will directly affect conversion of PAN fiber to carbon fiber. Oleic acid was used as post spinning treatment chemical solution to PAN fibers. The pretreated PAN fiber will be heated at $250^{\circ} \mathrm{C}$ and $800^{\circ} \mathrm{C}$. The fibers were studied using Fourier Transform Infra-Red (FTIR), X-ray Photoelectron Spectroscopy (XPS) and DSC to study the chemical change during heat treatment. PAN fibers treated with oleic acid have reduced the cyclization energy and increase oxygen and carbon content leading to high performance carbon fibers.
\end{abstract}

\section{Introduction.}

Carbon fiber was used in high performance composite due to excellence weigh to strength ratio. Carbon fiber reinforced composite became more important in aerospace, civil engineering, military, and motorsports, along with other competition sports [1-2]. Carbon fibers can be derived from pitch based, polyacrylonitrile (PAN) polymer or rayon based chemicals. However most high performance carbon fiber was converted from polyacrylonitrile (PAN) based polymer due to high carbon content after heat treatment process [3]. Polyacrylonitrile (PAN) polymer was spun to form polyacrylonitrile (PAN) fiber and treated with solution known as post spinning treatment. Post spinning were divided into three categories, such as modification through coating, impregnation with chemicals (catalytic modification) and drawing/stretching with plasticizer [4,5,6 ]. Previous study shows fatty acid derivatives react as coating agent to reduce the entangling, fluffy, fusion and fiber to fiber adhesion of the PAN precursor fibers during thermal stabilization process [7]. In this paper an attempt to prove that fatty acid without any derivative can give similar effect to fatty acid derivatives coating type post spinning modification process. The post spinning modifications indirectly affect and ease the stabilization in several ways such as reducing the activation energy of cyclization, decreasing the stabilization exotherm, increasing the speed of cyclization reaction and also improving the orientation of molecular chains in the fibers [8]. Recently, the stabilization process is found to play an important role in converting PAN fiber to an infusible stable ladder polymer that converts $\mathrm{C}=\mathrm{N}$ bonds to $\mathrm{C} \equiv \mathrm{N}$

${ }^{\text {a }}$ Corresponding author: shahruln@outlook.com

${ }^{\mathrm{b}}$ Corresponding author: zaki_abdullah@petronas.com.my

This is an Open Access article distributed under the terms of the Creative Commons Attribution License 2.0, which permits unrestricted use, distribution, and reproduction in any medium, provided the original work is properly cited. 
bonds and to develop crosslink between molecules of PAN which tend to operate at high temperatures, with minimum volatilization of carbonaceous material. The thermal stability of the stabilized fiber is attributed to the formation of the ladder structure due to cyclization of the nitrile groups in acrylic molecule and started from $180^{\circ} \mathrm{C}$ to $300^{\circ} \mathrm{C}$. Carbonization was an aromatic growth and polymerization in which the fiber would undergo heating process at a high temperature up to $800-3000^{\circ} \mathrm{C}$, typically to a $95 \%$ carbon content . Carbonization at $1000^{\circ} \mathrm{C}$ will produce carbon fiber in low modulus type and intermediate modulus or type II carbon fiber will produce at up to $1500^{\circ} \mathrm{C}$.[8]

\section{Experimental.}

The PAN fiber was produced by Fortafil Fibre Inc. with 50000 (50k) s filament per tow was used in the study. The fibers have 17 micron average diameter.

\subsection{Chemical treatment process.}

$10 \%$ oleic acid was dissolved in acetone with $10 \%$ weight by weight ratio. The PAN fiber was soaked into the solution for about 10 minutes and left to dry. The coated fibers was heated by batch in $250{ }^{\circ} \mathrm{C}$ and $800{ }^{\circ} \mathrm{C}$.

\subsection{Stabilization of fibers.}

Stabilization is a heat treatment process starting from $200^{\circ} \mathrm{C}$ to $300{ }^{\circ} \mathrm{C}$. In this study $250{ }^{\circ} \mathrm{C}$ temperature was chosen for PAN fibers treated and untreated with oleic acid. Both samples were heat treated in tube furnace with $1{ }^{\circ} \mathrm{C} / \mathrm{min}$ heating rate.

\subsection{Carbonization of fibers.}

The stabilized PAN fibers will undergo a carbonization process started at $800{ }^{\circ} \mathrm{C}$ with heating rate at 5 ${ }^{\circ} \mathrm{C} / \mathrm{min}$ in an inert atmosphere to produce carbon fiber. The treated and untreated samples with oleic acid were placed together in the tube furnace.

\subsection{FTIR study.}

The samples were characterized using attenuated total reflectance (ATR) FTIR model Nicolet iS5 with iD5 ATR attachment

\subsection{Differential scanning calorimetry(DSC) study.}

The samples were characterized using DSC model 821 with $10^{\circ} \mathrm{C} / \mathrm{min}$ heating rate from $30^{\circ} \mathrm{C}$ to $400{ }^{\circ} \mathrm{C}$. Nitrogen flow was set at $1 \mathrm{~cm}^{3} / \mathrm{m}$

\subsection{X-ray Photoelectron Spectroscopy (XPS) study.}

X-ray photoelectron spectra were recorded using a Omicron XPS spectrometer with a $\mathrm{Mg} \mathrm{K} \alpha$ X-ray source $(1254 \mathrm{eV})$. Wide scan was perform on the sample before narrow scanning on carbon and oxygen element. The data collected from the instrument were analyzed by CasaXPS software. 


\section{Result and Discussion.}

\subsection{FTIR Result.}

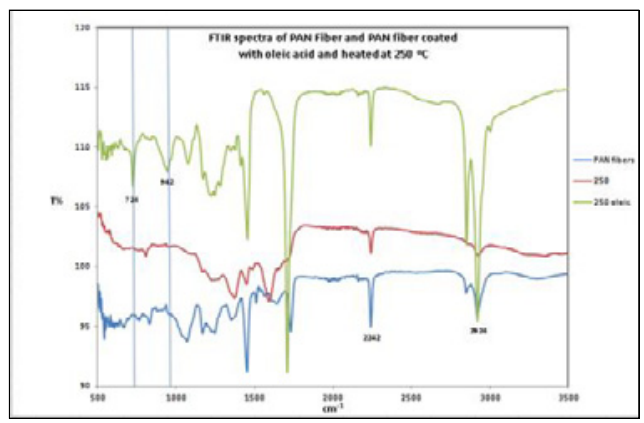

Figure 1. FTIR spectra of PAN Fiber and PAN fiber coated with oleic acid and heated at $250^{\circ} \mathrm{C}$.

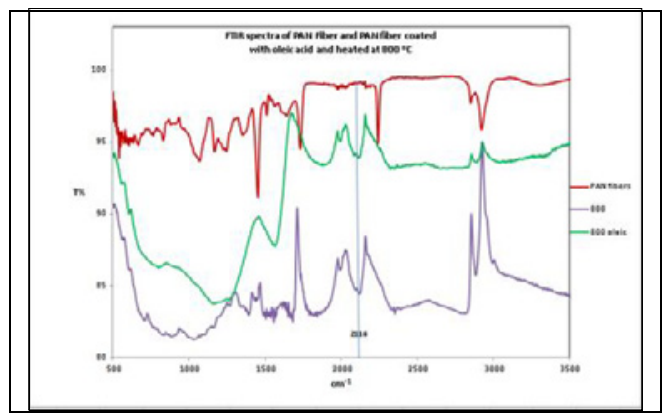

Figure 2. FTIR spectra of PAN Fiber and PAN fiber coated with oleic acid and heated at $800^{\circ} \mathrm{C}$

Figure 1 show FTIR spectral comparison between PAN fiber before and after heated at $250^{\circ} \mathrm{C}$. Before heated, PAN fiber show prominent peaks at 2924 and $2242 \mathrm{~cm}^{-1}$ due to stretching vibration of the methylene ( $\mathrm{CH} 2$ ) and the nitrile groups $(\mathrm{CN})$ in acrylonitrile structure. In figure $1,2242 \mathrm{~cm}^{-1}$ of cyanide $(-\mathrm{C} \equiv \mathrm{N})$ which is main functional group of PAN fibers gradually decrease in concentration when heated to $250^{\circ} \mathrm{C}$. In figure 1 , it is clearly shown the existing of a new peak in $1580 \mathrm{~cm}^{-1}$ region after heat treated to $250^{\circ} \mathrm{C} .1580 \mathrm{~cm}^{-1}$ was referred to double bonding of carbon $(\mathrm{C}=\mathrm{C})$ exist in cyclic form. The double bond only exists when heat treated at $250^{\circ} \mathrm{C}$. This suggests that intermolecular or intramolecular cross-linking might have taken place forming the cyclisation reaction. For $1731 \mathrm{~cm}^{-1}$, indicate the existent of carbonyl group in PAN fibers and was gradually decreased with increasing temperature. The carbonyl group was found in PAN fibers due to commoner exist in the polymer which is a common for PAN fibers manufacturing process in order to increase the plasticity effect to the fibers. Compound Methyl acrylate was often used as commoner in PAN polymer to produce the fibers.PAN fibers treated with oleic acid and heated at $250^{\circ} \mathrm{C}$ show interesting FTIR spectra pattern. Most of the peaks have significantly high intensity compared to untreated PAN fibers. At $2924 \mathrm{~cm}^{-1}$, sharp and high intensity peak referred to methylene $(\mathrm{CH} 2)$ was recorded in the spectra. This may due to methylene $(\mathrm{CH} 2)$ coming from oleic acid attach to stabilized PAN fibers surface. Sharp and high intensity peak at $1709 \mathrm{~cm}^{-1}$ show existent of carbonyl $(\mathrm{C}=\mathrm{O})$ derived from carboxylic acid which is a functional group of oleic acid. PAN fibers treated with oleic acid and heated at $250^{\circ} \mathrm{C}$ also show additional peaks at 724 and $942 \mathrm{~cm}^{-1}$ and was referred to rocking $\mathrm{CH}_{2}$ and $\mathrm{NO}$ formation.Figure 2 show FTIR spectral comparison between PAN fiber before and after heated at $800^{\circ} \mathrm{C}$. The FTIR spectra between PAN fibers coated and uncoated with oleic acid show almost similar pattern. Main 
peaks at $2885 \mathrm{~cm}^{-1}$ due to $\mathrm{CH}$ from aldehyde of ketone group. $2116 \mathrm{~cm}^{-1}$ was referred to $\mathrm{N}=\mathrm{C}-\mathrm{C}$ group. However PAN fiber treated with oleic acid and heated at $800^{\circ} \mathrm{C}$ has additional peak at $1570 \mathrm{~cm}^{-1}$ which was referred to $\mathrm{N}-\mathrm{H}$ bending in amide group

\subsection{Differential scanning calorimetry(DSC)}

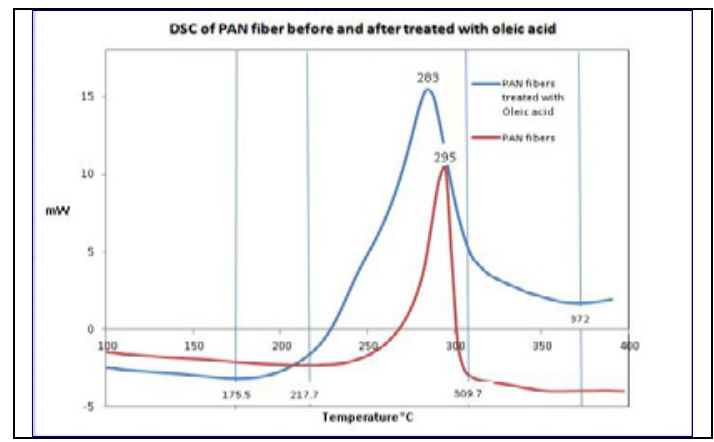

Figure 3. DSC of PAN fiber before and after treated with oleic acid.

As shown in figure 3, the range of the exotherm for PAN fibers was from $217.7^{\circ} \mathrm{C}$ to $309.7^{\circ} \mathrm{C}$ a spread of $92^{\circ} \mathrm{C}$ whereas for PAN Fibers treated with oleic acid range was from $175.5^{\circ} \mathrm{C}$ to $372^{\circ} \mathrm{C}$, a spread of $196.5^{\circ} \mathrm{C}$. Pan fiber treated with oleic acid has lower exorthermic peak at $283{ }^{\circ} \mathrm{C}$ as oppose to PAN fiber with exorthermic peak at $295{ }^{\circ} \mathrm{C}$. However, for Pan fiber treated with oleic acid, a shoulder appear in the graph, suggesting there are two exorthermic peak that may be came from oleic acid treatment. The broadening of the exothermic peak is probably contributed to the oleic acid that initiates cyclization at a lower temperature through an ionic mechanism.

\subsection{X-ray Photoelectron Spectroscopy (XPS)}

The data received from Omicron XPS was analyzed by CasaXPS software. All binding energy are measured in electron volt $(\mathrm{eV})$ and were referred to National Institute of Standards and Technology (NIST) X-ray Photoelectron Spectroscopy Database.

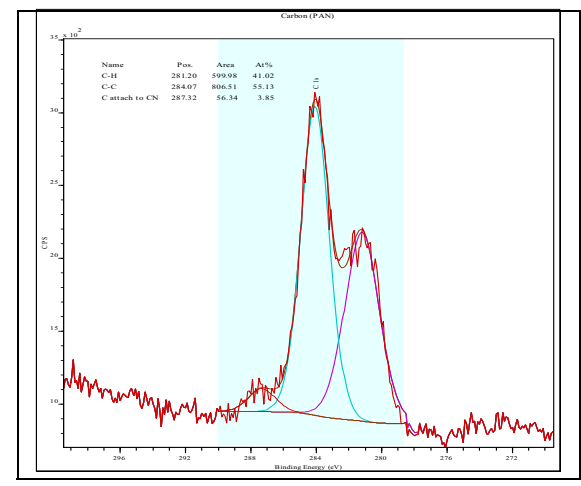

Figure 4.XPS spectra of PAN fiber.

Figure 4 show XPS spectrum of $\mathrm{C} 1 \mathrm{~s}$ for PAN fiber. After deconvulation, the spectra revealed 3 peaks at $281.20 \mathrm{eV}, 284.07 \mathrm{eV}$ and $287.32 \mathrm{eV}$. The three peaks can be assigned to $\mathrm{C}-\mathrm{H}, \mathrm{C}-\mathrm{C}$ and carbon attached cyanide carbon $(\mathrm{CN})$. It shows the monomer of PAN polymer as shown in figure 5. 


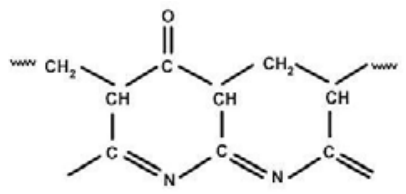

Figure 5. Polyacrylonitrile polymer.

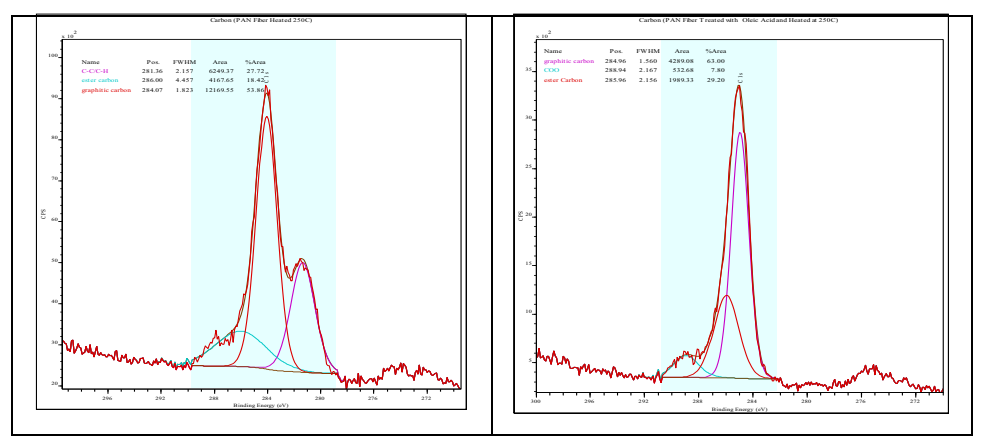

(A)

Figure 6. XPS spectrum of PAN fiber heated at $250^{\circ} \mathrm{C}(\mathrm{A})$ and oleic acid treatment (B)

After PAN fiber was heated at $250^{\circ} \mathrm{C}, \mathrm{C} 1 \mathrm{~s}$ XPS spectrum show 3 peaks centered at $281.36 \mathrm{eV}, 286.00$ $\mathrm{eV}$ and 284.07. All peaks are referred to $\mathrm{C}-\mathrm{H}$, ester carbon (COO-R) and $\mathrm{C}-\mathrm{C}$ or graphitic carbon. The carbon content (C-C), of PAN fiber heated at $250^{\circ} \mathrm{C}$ is almost similar to PAN fiber which was calculated at $53.86 \%$ and $55.13 \%$ respectively. However ester type carbon was found due to cyclization of PAN polymer in the fiber. In figure 6(B), graphitic carbon (C-C) has slightly increased to $63 \%$. This show oleic acid does help in cyclization process. Ester carbon content also increases compare to PAN fiber without oleic acid treatment. $288.89 \mathrm{eV}$ peak show carbon from carboxylic acid, a functional group of oleic acid.

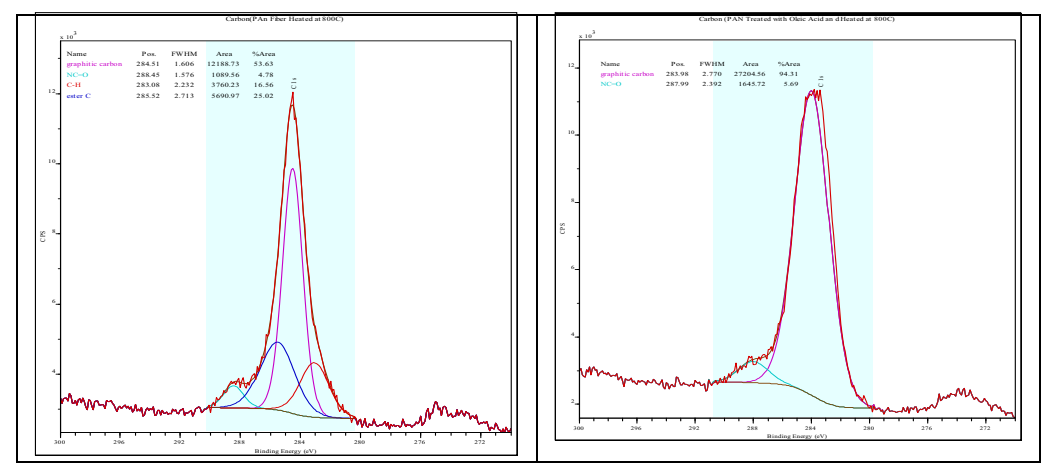

(C)

(D)

Figure 8. XPS spectra of PAN fiber heated at $800^{\circ} \mathrm{C}(\mathrm{C})$ and oleic acid treatment (D)

After heated at $250{ }^{\circ} \mathrm{C}$, the fiber was heated at $800{ }^{\circ} \mathrm{C}$ in inert environment. The $\mathrm{C} 1 \mathrm{~s}$ xps spectrum show 4 peaks after deconvulation. The peak represent graphitic carbon, C-C $(284.51 \mathrm{eV})$, amide carbon, $\mathrm{NC}=\mathrm{O}(288.45 \mathrm{eV})$, ester carbon $(285.52 \mathrm{eV})$ and $\mathrm{C}-\mathrm{H}$ carbon. Carbonization started at $800^{\circ} \mathrm{C}$ to $1500^{\circ} \mathrm{C}$ to form low to intermediate modulus carbon fibers. Figure $8(\mathrm{C})$ show the existence of ester carbon that indicate carbonization process not fully occur. Graphitic carbon content shows no significant increase around $53.63 \%$. However amide type carbon starts to exist on the surface of the fiber due to cyclization process. Figure 8(D) shows PAN fiber treated with oleic acid have higher carbon content at $94.31 \%$. This indicate oleic acid have important role in carbon fiber conversion process. 


\section{Summary}

PAN fiber coated with $10 \% \mathrm{w} / \mathrm{w}$ oleic acid play important role in lowering cyclization energy of PAN fiber to form carbon fibers. The coated PAN fiber could be fully preoxidized at lower temperature and reduce thermal stabilization temperature as indicate by the DSC. FTIR result show insertion of carboxylic acid to the polyacrylonitrile polymer has altered the structure, thus promoting early stabilization process that lead to thermal stability of the fibers before carbonization stage. This will assist aromatic growth of carbon structure with higher carbon content at carbonization stage. Higher carbon content of carbon fibers have higher mechanical properties as reported by previous studies. $[9,10]$

\section{References}

1. P.J. Sánchez-Soto, M.A. Avilés, J.C. del Río, J.M. Ginés, J. Pascual, J.L. Pérez-Rodríguez, Thermal study of the effect of several solvents on polymerization of acrylonitrile and their subsequent pyrolysis, J. Anal. Appl. Pyrolysis 59, 155-172 (2001).

2. X. Huang, Fabrication and properties of carbon fibers, Materials 2, 2369-2403 (2009).

3. T.-H. Ko, S.-C. Liau, M.-F. Lin, Preparation of graphite fibres from a modified PAN precursor, J. Mater. Sci. 27, 6071-6078 (1992).

4. L. Jie, Z. Wangxi, Structural changes during the thermal stabilization of modified and original polyacrylonitrile precursors, J. Appl. Polym. Sci. 97, 2047-2053(2005).

5. R.B. Mathur, O.P. Bahl, J. Mittal, Advances in the development of high performance carbon fibers from PAN precursor, Compos. Sci. Technol. 51,223-230 (1994).

6. J. Mittal, R.B. Mathur, O.P. Bahl, Post spinning modification of PAN fibres - a review, Carbon 35, 1713-1722 (1997).

7. X. Huang, Fabrication and properties of carbon fibers, Materials 2, 2369-2403 (2009).

8. Yusof,N.\&Ismail,A.,Post spinning and pyrolysis processes of polyacrylonitrile (PAN)-based carbon fiber and activated carbon fiber: A review,Journal of Analytical and Applied Pyrolysis 93,1 - 13 (2012)

9. Mittal, J.; Mathur, R.; Bahl, O. \& Inagaki, M.Post spinning treatment of PAN fibers using succinic acid to produce high performance carbon fibers,Carbon, 36, 893 - 897 (1998)

10. Gupta, A. \& Harrison, I. New aspects in the oxidative stabilization of PAN-based carbon fibers: II, Carbon, , 35, 809 - 818 (1997) 